\title{
An Evaluation of the Cost and Benefits of Applied Cosmetics Industry Marketing Best Practices: A Case Study of the Kenyan Market
}

\author{
Hemant Raj Singh Thakur $^{1}$ \& Dr. Peter Kiriri ${ }^{2}$ \\ 1, Chandaria School of Business, United States International University - Africa, Kenya \\ ${ }^{2}$ Corresponding Author, Chandaria School of Business United States International University - Africa, Kenya
}

Abstract: The purpose of this study is to develop an evaluation of the cost and benefits of applied cosmetics industry marketing best practices in Kenya. The research adopted a descriptive research design. Primary data was collected from respondents in Nairobi, Kiambu, and Nakuru counties in Kenya. Purposive technique was used to identify the counties while stratified sampling technique was used to identify the respondents in the counties. Data collection was done using structured questionnaires. Collected data was later coded, cleaned, analysed, and interpreted. The study found out that mass media advertisement marketing strategy is the most commonly used marketing strategy in Kenya. It is the least costly marketing strategy and offers the most marketing benefits. Further research is required to evaluate the interrelationship of the commonly used marketing strategies in the cosmetic industry. The practical implications of the study are that cosmetic businesses need to understand their businesses and identify which marketing strategies work for them. The value of this original research is to help organizations identify the marketing strategies that are commonly available and their different cost implications and benefits.

Key words- Cosmetics, Marketing strategies, Marketing strategy benefits, best practices, Kenyan market DOI: $10.7176 / \mathrm{JMCR} / 53-06$

\section{INTRODUCTION}

Cosmetics are categorized as perfume and eau de colognes (such as fragrances), make up (such as foundation creams, concealers, eye shadow, eye liners, lipstick), skin care products (such as facial creams, cleansing creams, skin moisturizers, skin lotion, and skin milk), hair care products (such as hair dye, hair shampoo, hair conditioners, hair treatment, hair relaxers), and special purpose cosmetics (such as sunscreen). Sometimes soaps are classified as cosmetics (JETRO, 2011).

The cosmetics industry is one of the leading industries in the world. This industry has employed millions of people all over the world. In addition to the manufacturers, wholesalers, retailers, and sales agents in the cosmetics industry, scientists are key players in this industry. For example in Europe, more than 26,000 scientists are employed. There are more than 33 scientific innovation centres in Europe that deal with cosmetics. Patent activity is one of the most used factors to determine the level of innovation and as studies reveal, in 2011 at least 6,000 patents were done in the cosmetic industry in Europe. Furthermore, at least 26,000 scientists were employed in the European cosmetic industry. The cosmetic industry supports very many jobs directly and indirectly which leads to the growth of a country's economy. For example, in Europe, 152 million people work directly in the cosmetic manufacturing businesses while approximate 1.6 million people work indirectly in the cosmetic industry value chain (RPA, 2016).

Africa is a complex continent because it has different lifestyles, ethnic groups, social and cultural groups. Africa has over a billion people and the population is still growing. Studies show that in 2065 Africa will have over 3 billion people. This number will be the combined population of China and India at that time. This shows that the African market potential is great. It is estimated that by the year 2030, the top 18 most populated African cities will have a disposable income of $\$ 1.3$ trillion. This will attract organizations seeking to grow their 
business away from the developed countries. All the big organizations in the cosmetic industry have implemented strategies that will enable them capture the rising African cosmetic industry that is expected to rise to approximately $\$ 1.8$ billion by 2018 . Rising economies such as Uganda and large markets such as Kenya and Ethiopia, increased middle class income, population growth, and increased urbanization are the factors that are increasing the demand for cosmetic products within the East African region (Redazione, 2017).

Kenya, Uganda, Ethiopia, Tanzania, and Mozambique are some of the countries in East Africa that have a high rate of growth and increased per capita income which leads to the demand of cosmetics products. Hair care cosmetics category is one of the sectors that is leading in the sale of cosmetic products in East Africa. Many women in Africa prefer natural hair products which are friendly to their hair type but these products are hard to find. This group of consumers prefer cosmetic products be customized to meet their needs. Studies show that 'afrocentric cosmetics' have a high demand in the East African market. The leading cosmetic organizations have realized that Western or Asian products are not selling in Africa as they would have expected. They have therefore introduced new products that are designed to work for the African consumer. Most consumers prefer international brands because they believe if a brand is popular in one market it is definitely a good product and will work for them too. The rise of multinational cosmetic businesses in East Africa is an indirect result of conducting business in the South African market (Colombini, 2017).

In order to attract the African consumers, it is necessary to tailor products that meet their needs and requirements. For example, L'Oreal one of the giant players in the cosmetic industry launched 'the L'Oréal Institute for Ethnic Hair and Skin Research' in Chicago and an assessment centre in South Africa for studying and understanding consumer development. To attract more consumers to a brand, the multinational businesses operating in East Africa are packaging the cosmetic products in smaller packages to reduce the cost of the product which might be a problem to low income earners. Consumers in the East African market are also aware of the counterfeit cosmetic products being sold in the market. Studies have shown that $30 \%$ of the cosmetic products being sold are counterfeit or have been manufactured from low quality raw products. This is pushing consumers to buy very expensive cosmetic products to ensure they are buying high quality products. Consumers in East Africa are now traveling to foreign markets such as Dubai in search of high quality cosmetic products (Redazione, 2017).

\section{The Marketing Strategies}

\section{LITERATURE REVIEW}

Different players in the cosmetic industry are always looking for new marketing practices to ensure more consumers purchase the products. Organizations in the cosmetic industry use different marketing strategies to achieve their goals and objectives. Celebrity marketing is one of the major marketing strategies applied globally. It is a form of marketing strategy where organizations look for celebrities in a given market and use their endorsements as the main theme in their marketing strategies (Ambrois et al, 2014). The celebrity marketing strategy is applied through two main tactical approaches. The first approach is the use of advertisements. In this case, celebrities are used in advertisements to endorse a product. Furthermore, this approach ensures the target is the customer base and markets who consider the celebrities as their role model. The fact that the celebrities endorse the products shows that the products are of high quality. 
Celebrity marketing can be very effective especially where a celebrity has a large fan base. The celebrities look up to the celebrity as their role model and they trust that their celebrity uses the best products. Celebrity endorsements create a high customer loyalty rating for a given product. However, this should be discussed on the context of the existing market cultures. In this regard, the effectiveness' of this strategy is hedged on the presence of a highly collective culture in a market. This is because such a culture allows for the emergence of role models who are followed and copied by their society members. The second approach in the use of celebrity marketing is through the use of brand ambassadors. This enables the celebrities to participate and interact with the customers as they promote the brands while engaging in social activities (Hollensen \& Schimmelpfennig, 2013).

Product placement is an ideal strategy applied in the global cosmetic industry. As Liang, Hsiao and Cheng (2015) described it, the product placement strategy includes the use of mass media communications such as TV shows and movies to market a product. In this case, rather than actively generating advertisements, the use of product placements ensures that the actors and the movies use the targeted products. A review by Cha (2016) demonstrated on the value of adopting this strategy. In this regard, the evaluation noted that the use of product placement increased the viewing of the advertisements. This was through realising that customers were unwilling to watch commercials and advertisements, but could associate and identify with products used on a TV or movie show. Consequently, this creates the impression that the products are of good quality and are reliable. This is especially applied in the cosmetics industry. Nevertheless, the effectiveness of this strategy is pegged and hedged on the availability of a high existing and potential customer base that participates and has access to the TV shows and movies. Therefore, in nations where the entertainment industry is yet to develop fully, and the audience is limited to a given population cluster, the strategy is ineffective.

Organizations in the cosmetic industry use the sales force marketing strategy to increase customer reach. An organization should communicate its objectives and strategies that have been planned in order to have an effective sales force. The sales force should be constantly informed about the organization's direct marketing plans, promotions, advertising, or any other marketing plan an organization might have. Organizations should also include the trade shows and conferences the sales force need to attend so that they can plan on what is required to be done. Trade shows and exhibitions are excellent for introducing an organization's new products. The sales force is usually the best marketing strategy to use in such some circumstances since demonstrations can even be done if required. The sales force is able to give superior customer value when they perform activities such as new customer acquisition, customer relationship development, customer trust building, and customer retention (Cron \& Craven, 2010).

Mass media advertisements on television, radio, newspapers and magazines, and social media are the most commonly used forms of advertisements. Organizations in the cosmetic industry use mass media advertisements because they guarantee a wide geographical area coverage. Social media platform such as Facebook, Twitter, LinkedIn, SnapChat, Pinterest, Google AdWords among others are used by organizations to market their cosmetic products. Small and medium enterprises can also afford to put their advertisements on these platforms at a very low cost. It is important for an organization to determine what it aims to achieve in order to choose the best media that addresses its marketing needs. It is also important to note that one mass 
media advertisement form might work for one organization but may not work for another organization since all organizations are different. The stats related to an organization's ads that are provided by different online advertising platforms help show what is working for an organization and what is not (Smale, 2017).

\section{Cost Implications}

Each marketing strategy has costs that must be evaluated in terms of how effective the strategy will be in meeting an organization's objectives. For example, an organization could spend so much money to have a celebrity marketing strategy because the said celebrity is popular but the celebrity may not be the right person for a particular product. For example, it would be more appropriate to have a sports celebrity endorse a sports product. An organization may also decide to use an email campaign which may not be effective if the emails land in the recipient's spam filters. It is advisable for an organization to weigh the costs and benefits of a marketing strategy before spending money and time on it (Johnston, 2017).

High marketing cost is an organizations major concern when deciding which marketing strategy to adopt. For example, celebrity marketing is a marketing strategy that has been used over the years because it reaps huge rewards for a brand but it has its own share of pitfalls. An organization may spend so much on a celebrity endorsement deal and fail to achieve its intended objectives. The more popular a celebrity may be, the more an organization may spend on an endorsement deal. Celebrity marketing is very effective in creating brand awareness but it is not a marketing strategy that small businesses can afford due to the high costs that are involved (Gunelius, 2013). Organizations using product placement marketing strategy incur costs depending on various factors. For example the cost of a product placement will depend on the type of movie/TV show/music video, the size of the audience that is expected, the cast of the movie, the directors, how big the product placement will be, and who else would like to place the product in their show (Jones, 2016).

Sales force marketing strategy also has its own costs. Organizations must constantly train the sales force so as to ensure they are aware of their duties, they are aware of the organization's objectives, and are able to foster good customer relationships. When organizations use intermediaries to market their products, they are required to pay them a salary, commission, or offer them a discount. Organizations using the sales force marketing strategy also incur extra expenses when the sales force travel from one geographical area to another (Suttle, 2017). Mass media advertising marketing strategy has different factors that affect its cost. For example, network TV pricing depends on the distribution pricing and content type. Social media marketing can be divided into different categories, generally by channels or services. Not every social media channel is good for a business, therefore organizations should evaluate which social media channel is less costly while still meeting the organization's needs. For example, Facebook and Twitter would be the most affordable social media options for a small business (DePhillips, 2011).

\section{Marketing Strategy Benefits}

Implementing a good marketing strategy is one of the most important things for a product to be successful in the marketplace. Organizations that have good marketing strategies are able to tap new markets. For example, when popular celebrities endorse a brand, all their fans are encouraged to purchase the product. 
This is because the fans look up to their celebrities as their role models. The more popular the celebrity is, the larger the fan base an organization gets to attract (Mello, 2014). An effective marketing strategy increases consumer reach. For example, having a sales force strategy increases reach and penetration within a market. A sales force is able to get products to consumers who cannot find their regular products at the local retail shops. A sales force is also able to increase an organization's presence in a market (Bhasin, 2016).

Trust and credibility is a benefit an organization achieves by having an effective marketing strategy. Celebrity marketing strategy builds trust and credibility for a brand because celebrities are viewed as idols by their fans. Whatever product they endorse is deemed to be of high quality or superior than the competitor products. Getting a celebrity with millions of fans to endorse a product ensures all these people will be purchasing an organization's product which in turn improves an organization's brand market value and reputation (Mello, 2014). A marketing strategy can give an organization a competitive advantage. Placing a product in a popular movie or TV show or having a popular celebrity endorse a brand can give an organization a competitive advantage. Organizations should research on which celebrity is currently trending in order to get value for their money. Social media platforms such as Pinterest, Instagram, and Tumblr can help an organization find out who is currently trending. For these strategies to be more effective in creating a competitive advantage, organizations should research on the celebrities likes and dislikes so as to be in a better position to know which type of products a celebrity can endorse and how a product can be placed in a movie or TV show (Dudovskiv, 2012).

An effective marketing strategy creates product and brand awareness. For example, sales force strategy ensures consumers who are in remote areas where no mass media advertisement forms are available know of new products in the market. Celebrity endorsements also create curiosity to see what the new product is and what it does. Previous studies have also shown that celebrity endorsements enable consumers remember a product (Khatri, 2006).

\section{METHODOLOGY}

The study adopted a descriptive research design. A population of 240 manufacturers and wholesalers of cosmetic products were targeted in three counties in Kenya. These counties were Nairobi, Kiambu, and Nakuru counties. The researcher used purposive sampling to identify the counties to be used in the study. From this population, a sample size of 150 respondents was identified using the Yamane's formula. Stratified sampling technique was used to get the number of respondents in each county. The primary method that was used to collect data from the respondents was a structured questionnaire. The questionnaire was divided into four sections where the first section sought the demographic information of the respondents, the second section was based on the commonly used marketing strategies, the third section was based on the cost implication of different marketing strategies and the fourth section was based on the benefits of different marketing strategies. The questionnaire had a 5 point likert scale where $1=$ Strongly Disagree, $2=$ Disagree, $3=$ Neutral, $4=$ Agree, and $5=$ Strongly Agree

\section{RESULTS AND DISCUSSIONS}

The results of the study indicate that celebrity marketing strategy, product placement marketing strategy, sales force marketing strategy, and mass media advertising strategy are the cosmetic industry best 
applied marketing practices. The study further revealed that, of the four commonly used marketing strategies, mass media advertising strategy was the most used marketing strategy while sales force strategy was the most effective and preferred marketing strategy. Table 1 below shows that the study revealed that majority of the respondents at $73 \%$ strongly agreed that mass media advertisement strategy was the most used marketing strategy because it is economically affordable and has the ability to reach consumers in a wide geographic area. The most commonly used mass media advertisement forms were found to be television, radio, newspapers and magazines, and social media (Facebook and Twitter). Cosmetic businesses prefer sales force as a marketing strategy because of its ability to reach consumers who have challenges accessing different mass media advertisement forms. According to Petryni (2007), use of sales force marketing strategy is effective because the direct contact with the consumers encourage product trial and immediate feedback. Organizations are also able to manage their customer relationships through the sales force marketing strategy.

Table 1: Commonly used Marketing Strategies

\begin{tabular}{|l|r|r|r|r|r|r|r|r|r|}
\hline \multicolumn{10}{|c|}{ Marketing Strategies } \\
\hline & $\begin{array}{l}\text { Strongly } \\
\text { Disagree }\end{array}$ & Disagree & Neutral & Agree & $\begin{array}{l}\text { Strongly } \\
\text { Agree }\end{array}$ & Total & $\mathrm{N}$ & \multicolumn{1}{|c|}{$\begin{array}{l}\text { Mean } \\
\text { Dev. }\end{array}$} \\
\hline $\begin{array}{l}\text { Celebrity } \\
\text { Marketing }\end{array}$ & $\%$ & $1 \%$ & $3 \%$ & $33 \%$ & $63 \%$ & $100 \%$ & 101 & 4.58 & .604 \\
\hline $\begin{array}{l}\text { Product } \\
\text { Placement }\end{array}$ & $\%$ & $1 \%$ & $27 \%$ & $5 \%$ & $67 \%$ & $100 \%$ & 101 & 4.39 & .916 \\
\hline $\begin{array}{l}\text { Sales } \\
\text { Representatives }\end{array}$ & $1 \%$ & $18 \%$ & $12 \%$ & $40 \%$ & $29 \%$ & $100 \%$ & 101 & 3.77 & 1.085 \\
\hline $\begin{array}{l}\text { Mass Media } \\
\text { Advertisements }\end{array}$ & $\%$ & $\%$ & $15 \%$ & $12 \%$ & $73 \%$ & $100 \%$ & 101 & 4.58 & .738 \\
\hline
\end{tabular}

Celebrity marketing strategy was found to be the most cost intensive marketing strategy. 52\% of the respondents strongly agreed that celebrity marketing was the most cost intensive marketing strategy and these results go hand in hand with Gunelius (2013) who argues that celebrity marketing maybe effective because popular celebrities may influence their large fan base to purchase a certain product but this strategy is so costly and small businesses may not afford to sign the endorsement deal. 18\% of the respondents found product placement marketing strategy expensive especially if the product is going to be placed in a popular TV show or a movie with a popular cast and directors. Jones (2016) notes that product placement agencies can charge $\$ 60$ thousand to $\$ 150$ thousand for placing a single product and this cost can even be higher if a brand has multiple products. A correlation test revealed that marketing benefits and marketing costs have a weak positive linear relationship at $\mathrm{r}$ 0.203: $\mathrm{p} \leq 0.05$ ( 2 tailed). This showed that as a cosmetic business uses a marketing strategy that has more benefits, the marketing strategy costs will also slightly increase. 
Table 2: Correlations between Marketing Costs and Marketing Benefits

\begin{tabular}{|l|l|r|r|}
\hline \multicolumn{2}{|c|}{ Correlations } \\
\hline \multirow{3}{*}{ Marketing Costs } & Pearson Correlation & Marketing Costs & Marketing Benefits \\
\cline { 2 - 4 } & Sig. (2-tailed) & 1 & $.203^{*}$ \\
\cline { 2 - 4 } & $\mathrm{N}$ & & .050 \\
\hline Marketing Benefits & Pearson Correlation & $.203^{*}$ & 94 \\
\cline { 2 - 4 } & Sig. (2-tailed) & .050 & 101 \\
\cline { 2 - 4 } & $\mathrm{N}$ & 94 & \\
\hline *. Correlation is significant at the 0.05 level (2-tailed). & & \\
\hline
\end{tabular}

\section{CONCLUSION AND RECOMMENDATIONS}

This study sought to evaluate the costs and benefits of applied cosmetics industry marketing best marketing practices. Businesses in the cosmetic industry seek marketing strategies that are the most effective but with the least cost implications. The study revealed that different marketing strategies have different benefits and different cost implications. Mass media was found to be the most used marketing strategy because of its economic affordability and its ability to offer more benefits while sales force strategy was found to be the most effective and preferred marketing strategy. Celebrity marketing strategy was found to be the most cost intensive marketing strategy.

Based on the findings of the study, the organizations should use a combination of different marketing strategies to achieve better results. For example, the businesses in the cosmetic industry should use mass media advertising strategies and sales force strategy to achieve higher results. Businesses in the cosmetic industry are different and may require different marketing strategies. This means that, a marketing strategy may give one organization more benefits but may not be beneficial to another organization. Organizations should evaluate which marketing strategies give them more benefits. Further studies should be carried out to investigate the interrelationships between the different marketing strategies that are used by the cosmetic industry.

\section{REFERENCES}

Ambroise, L., Pantin-Sohier, G., Valette-Florence, P., \& Albert, N. (2014). From endorsement to celebrity cobranding: Personality transfer. Journal of Brand Management, 21(4), 273-285.

Bhasin, H. (2016). Advantages of Decentralized Sales Force. Retrieved from: https://www.marketing91.com/advantages-decentralized-sales-force

Cha, J. (2016). Product placement in movies: perspectives from motion picture firms. Journal of Media Business Studies, 13(2), 95-116.

Colombini, M. (2017). Africa: The Next Frontier of Cosmetics. Retrieved from: http://www.kosmeticaworld.com/2017/04/01/africa-next-frontier-cosmetics/

Cron, W. L. \& Cravens, D. W. (2011). Marketing Strategy. USA: John Wiley \& Sons.

DePhillips, K. (2011). How much does Social Media Marketing Cost. Retrieved from: https://www.contentfac.com

Dudovskiv, J. (2012). Product Placement as an Effective Marketing Strategy. Retrieved from: https://researchmethodology.net/product-placement-and-brand-placement/

Gunelius, S. (2013). Can Small Businesses Really Afford Celebrity Endorsements? Retrieved from: https://www.forbes.com/sites/work-in-progress/2013/09/17/can-small-businesses-really-afford-celebrityendorsements/\#10bb7a83e072 
Hollensen, S., \& Schimmelpfennig, C. (2013). Selection of celebrity endorsers: A case approach to developing an endorser selection process model. Marketing Intelligence \& Planning, 31(1), 88-102.

JETRO. (2011). Guidebook for Export to Japan.

Johnston, K. (2017). Advantages and Disadvantages of a Marketing Strategy. Retrieved from: $\mathrm{http}: / /$ smallbusiness.chron.com/advantages-disadvantages-marketing-strategy-53961.html

Jones, S. (2016). How to \#29: How much does Product Placement Cost. Retrieved from: http://blog.hollywoodbranded.com/how-much-does-product-placement-cost

Khatri, P. (2006). Celebrity Endorsement: A Strategic Promotion Perspective. New Delhi: Indian Media Study Journals, 1(1).

Liang, A. R. D., Hsiao, T. Y., \& Cheng, C. H. (2015). The effects of product placement and television drama types on the consumer responses of college students. Asia Pacific Journal of Tourism Research, 20(11), $1212-1233$

Mello, J. (2014). The Pros and Cons of Celebrity Marketing. Retrieved from: https://product2market.walkme.com/pros-cons-celebrity-marketing/

Petryni, M. (2017). Direct Sales Model Advantages. Retrieved from: http://smallbusiness. chron.com/directsales-model-advantages-32207.html

RPA (2016). Socio-economic contribution of the European cosmetics industry. Belgium: The personal Care Association

Redazione. (2017). Africa: The Next Frontier of Cosmetics. Retrieved from: http://www.kosmeticaworld.com/2017/04/01/africa-next-frontier-cosmetics

Smale, T. (2017). The 6 Best Advertising Strategies for Small Business. Retrieved from: https://www.entrepreneur.com/article/273913

Suttle, R. (2017). The Disadvantages of Direct Selling. Retrieved from: http://smallbusiness.chron.com/disadvantages-direct-selling-23209.html 